\title{
Gelişmekte Olan Ülkelerde Doğrudan Yabancı Sermaye Yatırımları ile Ekonomik Büyüme İlişkisinin Ekonometrik Analizi ${ }^{1}$
}

\author{
Hüseyin AĞIR \\ Prof. Dr., Kahramanmaraş Sütçü İmam Üniversitesi, İIBF, İktisat Bölümü \\ huseyinagir@hotmail.com \\ Orcid ID: https://orcid.org/0000-0003-1642-2876 \\ Merve RUTBIL \\ Uzman \\ merverutbil@gmail.com \\ Orcid ID: https://orcid.org/0000-0001-5158-0082
}

\begin{abstract}
Öz
Doğrudan yabancı sermaye yatırımlarının ekonomik büyümeyi olumlu etkilemesi beklenmektedir. Doğrudan yabancı yatırımlar gittikleri ülkelerde tasarruf yetersizliklerini telafi ederek, beşeri kaynakların arttırılmasına ve gelişimine katkıda bulunabilirler. Teknik bilgiyi teşvik ederek, pazarlama yeteneği ve yönetim sistemlerini iyileştirebilirler. Teknoloji transferi yoluyla yeni üretim tekniklerini geliştirerek ve yeni pazarlara açılarak üretimde verimlilik ve etkinliği arttırabilirler. Üretim artışını ihracata yönlendirerek ihracatı teşvik edebilirler. Sahip olduğu bilgi birikimi sayesinde işgücünün kalitesini arttırarak istihdama da katkı verip, ekonomik büyümeyi olumlu etkileyebilirler.

$\mathrm{Bu}$ çalışmanın amacını gelişmekte olan ülkelerde doğrudan yabancı sermaye yatırımları ile ekonomik büyüme arasındaki ilişkiyi test etmek oluşturmaktadır. Bunun için, üst-orta gelirli ülkeler içerisindeki seçilmiş 20 gelişmekte olan ülke ekonomisinin 1985-2017 dönemi verileri kullanılarak, yeni nesil panel ekonometrik analiz yöntemleri kullanılarak, doğrudan yabancı sermaye yatırımları ile ekonomik büyüme arasındaki ilişki, eşbütünleşme ve nedensellik testleriyle tahmin edilmiştir. Sonuç olarak, söz konusu ülkelerde doğrudan

\footnotetext{
${ }^{1}$ Makale Geliş/Kabul Tarihi: 13.06.2019 / 24.09.2019

Künye Bilgisi: Ăgır, H., Rutbil, M. (2019). Gelişmekte Olan Ülkelerde Doğrudan Yabancı Sermaye Yatırımlart ile Ekonomik Büyüme Ilişkisinin Ekonometrik Analizi. Kahramanmaraş Sütçü İmam Üniversitesi Sosyal Bilimler Dergisi, 16 (2), 469-488. DOI: 10.33437/ksusbd.577849
} 
yabancı sermaye yatırımlarının ekonomik büyümeye katkı sağlamadı̆̆ bulgulanmıştır.

Anahtar Kelimeler: Doğrudan Yabancı Sermaye, Gelişmekte Olan Ülkeler, Yapısal Kırılmalı Panel Eşbütünleşme, Panel Nedensellik.

\title{
Econometric Analysis of the Relation Between \\ Foreign Direct Investments and Economic Growth in Developing Countries
}

\begin{abstract}
Foreign direct investments are expected to affect economic growth positively. Foreign direct investments may contribute to the increase and the development of human capital by compansating for the lack of savings; improve marketing skills and management systems through stimulating technical knowledge; increase productivity and efficiency in production through developing new production techniques by technology transfers, and entering into new markets; provide incentives to export by directing production excesses to exporting; and affect economic growth positively through increasing the quality of the labor force owing to the accumulation of knowledge.

This study aims to test the relation between foreign direct investments and economic growth in developing countries. To test this relation, new generation panel econometric analysis methods, cointegration and causality tests, are applied on selected 20 developing countries out of upper-middle income countries for the period of 1985-2017. In conclusion, in these countries, foreign direct investments did not contribute to the economic growth.
\end{abstract}

Keywords: Foreign Direct Investments, Developing Countries, Panel Cointegration with Structural Break, Panel Causality.

\section{GİRIŞ}

Doğrudan yabancı sermaye yatırımları (DYY) yabancı yatırım türlerinden birisidir. Yabancı yatırım kavramı bir ülkede yerleșik kiși ve/veya kuruluşların kendi ülkeleri dışındaki bölgelerde yatırımlarını gerçekleştirmesi olarak tanımlanmaktadır. Bu bakımdan DYY literatürde "özel yabancı sermaye yatırımları", "dolaysız yabancı sermaye yatırımları", "doğrudan dış yatırımlar", biçiminde farklı isimlerle de ifade edilebilmektedir (Aydın, 2015:3-4). Kavramın farklı ülkelerde farklı şekillerde ifade edilmesi ile ortaya çıkan veri elde etme zorlukları ile tutarsızlıklarının ortadan kaldırması için OECD ve IMF çalışmaları 
kapsamında DYY ortak bir tanım kapsamında, "bir ekonomide yerleşik işletmelerin, başka bir ülkede üretim tesisi kurması veya başka bir ülkede bulunan mevcut üretim tesislerini satın alarak faaliyette bulması" şeklinde açıklanmaktadır (Seyidoğlu, 2017: 665).

Öte yandan ekonomik büyüme kavramıla anlatılmak istenen şey ise, bir ekonomide bir dönemde reel olarak üretilen her şeyin önceki dönem reel üretiminden farkı şeklinde ifade edilebilir. Nitelikten ziyade niceliksel (sayısal) bir değeri ifade etmektedir. Ülkelerin sahip olduğu emek, sermaye, doğal kaynaklar ve teknoloji düzeylerine göre büyümeleri de farklılaşabilmektedir. Ekonomik büyüme, ya tam istihdam düzeyinin altındaki ekonomik kaynakların arttır1mas1 yoluyla ya da tam istihdam düzeyinde, kaynaklara yenilerinin eklenmesiyle sağlanabilmektedir (Taban, 2014: 3).

Küreselleşme süreci ile birlikte yabancı sermaye yatırımlarının önemi de artmaktadır. DYY, dünya genelindeki kaynakların etkin ve verimli dağılımını sağlaması açısından oldukça önemlidir. Özellikle Gelişmekte Olan Ülkelerin (GOÜ) en önemli sorunlarından birisinin yetersiz sermaye olması nedeniyle bu ülkeler için DYY kalkınmanın önemli bir dinamiği olarak kabul edilmektedir (Sabır, 2001: 23). Bu bakımdan sermaye ihraç eden ülkeler için sermaye birikimi fazlalığının değerlendirilmesi ve rekabet güçlerini artıran DYY, sermaye ithal eden ülkelerde ekonomik büyümeye, üretime, ihracat kapasitesinin artırılmasına, teknolojik gelişmenin sağlanmasına, istihdam ve işgücü niteliğinin artmasına vb. katk1 sağlayabilmektedir (Bayraktar, 2003: 2). Diğer taraftan DYY'ler ihracatçıları ve yatırım yapmak isteyenleri özendirerek, özel sektörü teşvik edip beşeri kaynakların kapasitesini de arttırabilmektedir (Gerni vd., 2014: 2).

DYY'nin, yatırımcının yatırımda bulunduğu ülke dışındaki kuruluşun mülkiyetine kısmen veya tamamen sahip olması, yönetim ve denetimini elinde bulundurması bu yapının en önemliği özelliği olarak görülmektedir (Bal ve Göz, 2010: 452). DYY, yatırım faaliyetlerini birden fazla ülkede yürüten ve üretimle ilgili temel kararları tek merkezden alan ve şirketlerin kararlarını etkileyen çok uluslu şirketler tarafindan yürütülmektedir. Bu kuruluşların üretim faaliyetleri; geriye bağıntılı, ileriye bağıntılıri ve yatay bağıntılı üretim faaliyleti olarak sinıflandırılmaktadır (Tandırcıoğlu ve Özen, 2003: 106): Geriye bağıntılı üretim faaliyetleri, daha çok doğal kaynakları işletme açısından faaliyette bulunan kuruluşların kendi sanayi üretimleri veya dünya pazarlarına açılan diğer ülkelerdeki kuruluşları için gerekli olan hammadde kaynaklarının sağlanması, işlenmesi ve satışı gerçekleştirilmektedir. İleriye bağıntılı üretim faaliyetleri, ana merkezin yabancı ülkelerdeki satış faaliyetlerinin düzenlenmesi veya ana merkezin bulunduğu pazarların sınırlı olması nedeniyle diğer ülkelerde yatırımın yapılma durumlarını kapsamaktadır. Yatay bağıntılı üretim faaliyetleri ise, üretim faaliyetlerinin en yaygın biçimde kullanıldığı kısım olarak nitelendirilmektedir. 
Yatırımda bulunan ülkedeki bağlı şirkete sermaye yoluyla birlikte lisans, teknik bilgi (know- how) ve emek gücü akışının gerçekleşmesi ile üretim yapılması sağlanmaktadır.

DYY'nin, iyi bir şekilde planlanması ve etkin yönlendirilmesi beraberinde üretim artış1, istihdam artı̧s, gelirde ve ihracatta iyileşmelere sebep olabilmektedir. Ucuz yabancı faktör kullanımı ve üretim maliyetlerinin düşürülmesi ve DYY'nin teşvik ettiği dövizler, uzun dönemde ithalatı ikame edici ve ihracatı arttırıcı etkiler oluşturarak ev sahibi ülkenin (Özkan, 2005: 61) ödemeler dengesi açığının kapatılmasını da sağlayabilmektedir. Çeşitli ülkelere giden DYY'deki artışlar, bunların miktarı ve niteliği bu ülkelerin büyüme performanslarını önemli ölçüde etkileyebilmektedir (Özdemir, 2011: 13; Dereli, 2018: 146). DYY ile birlikte ülkelerin diğer ülkelerle olan ilişkilerinin ekonomik, siyasi ve sosyal boyutları giderek genişler. Ülkeler arası ilişkilerin yoğunlaşması sermaye ihraç eden ülkelerle siyasi canlılıklar meydana getirir. Ekonomiye sağladığı katkılardan dolayı, DYY'nin önemi gittikçe artmaktadır (Akyol, 2013: 24).

DYY'nin, ülke ekonomilerine sağladığı olumlu etkilerin yanı sıra bir takım olumsuz etkilerinden de söz edilebilir. Buna göre, DYY, geldiği ülkede önemli sektörlerin denetimini ele geçirerek ekonomi yönetiminde söz sahibi olma özelliği kazandırabilir. Böylelikle ülke ekonomisinde bütünlügün bozulmasına neden olabilir.Daha üstün teknoloji ile gelen yabancı yatırımcılar, yerli firmalar üzerinde haksız rekabet ortamı oluşturabilir (Mucuk ve Demirsel, 2009: 366 ). DYY, yatırımın yapıldığı ülke ekonomisine girerken ve çıkarken piyasalarda dalgalanmalara neden olabilir. DYY, ev sahibi ülkede borçlanarak faiz oranlarının artmasına ve iç talebin daralmasına neden olabilir (Akyol, 2013: 25). Kısa dönemde DYY, gittiği ekonomilerde bazı olumsuzluklara yol açabilirse de, uzun dönemde hem yatırımcı hem de ev sahibi ülkeye kazanımları söz konudur. Bilgiye dayalı rekabet edilebilir ortamlar oluşturmak, uygun yasal düzenlemeler sayesinde gerek yerli ve gerekse yabancı yatırımların ekonomiye olumlu katkı yapması olasılı̆̆ını da artıracaktır (Bayraktar, 2003: 19 ).

Bu çalışmanın amacını, Dünya Bankasının sınıflandırmasında üst -orta gelir grubu olarak kategorize edilen gelişmekte olan ülkelerde, DYY'nin ülkelerin ekonomik büyümelerine etkilerinin araştırılması oluşturmaktadır. Bu çalışma öncelikle üst-orta gelir grubundaki ülkeleri örneklem olarak analize konu ettiğinden, ikincisi de çalışmada kullanılan yeni nesil panel ekonometrik tahminlerden dolayı literatüre katkıda bulunacağı düşünülmektedir. Data aralığının uzunluğu dikkate alınarak seçilmiş üst orta gelir grubundaki 20 gelişmekte olan ülkenin 1985-2017 verisiyle ulaşılan tahmin sonuçları, söz konusu ülkelerde DYY'ler ile ekonomik büyüme arasında uzun dönemli bir ilişki 
olmadığını, dahası bu ülkelerde DYY'nin ekonomik büyümenin nedeni olmadığını ortaya koymaktadır.

\section{LITERATÜR TARAMASI}

İlgili yazında DYY'ler ile ekonomik büyüme ilişkisi üzerine geniş bir literatürün olduğu görülmektedir. Konunun hem ülke grupları hem de ülke örnekleri şeklinde ele alındığı başka bir ifadeyle zaman serileri ve panel ekonometrik analizlerin yapıldığı ve birbirinden farklı değişkenler yardımıyla değişik ekonometrik yöntemlerle elde edilen sonuçların literatürü zenginleştirdiği anlaşılmaktadır. Teorik olarak beklenen durum DYY'lerin eknomik büyümeyi olumlu etkilemesi yönündedir. Bununla birlikte yapılan ampirik çalışmalar arasında tam bir görüşbirliğinin bulunmadığı da açıktır. Çalışmalardan bazıları teorik beklentilerle uyumlu bir şekilde DYY'lerin ekonomik büyümeyi olumlu etkilediği şeklinde sonuç verirken (Yılmaz, 2008: 83-84): Blomström vd., (1992), Balasubramanya vd., (1996), Shan vd., (1997), Barrell ve Pain (1997), Borensztein vd., (1998), Bende-Nabende ve Ford (1998), De Mello (1999), Ito (1999), Konings (1999), Berthélemy ve Démurger (2000), Nair-Reichert ve Weinhold (2001), Obwona (2001), Calvo ve Sanchez-Robles (2001), Chakraborty Basu (2002), Choe (2003), Basu vd., (2003), Hansen ve Rand (2004), Chowdhury ve Mavrotas (2005), Khawar (2005), Kottaridi (2005); diğer bir takım çalışmalarda ise değişkenler arasındaki ilişkide belirsiz sonuçların ortaya konulduğu görülmektedir: Kholdy (1995), Mbekeani (1997), Bashir (1998), Agosin ve Mayer (2000), Ericsson ve Irandoust (2001), Carkovic ve Levine (2002).

Öte yandan, DYY'lerin büyüme üzerine etkilerini ele alan çalışmaların sonuçları, genelde DYY'lerin ekonomik büyümeyi artırıcı etkilerinin ortaya çıkabilmesi için gelişmekte olan ülkelerin uygun-destekleyici yatırım ortamını hazırlaması ve minimum bir kalkınma düzeyine erişmiş olması gerekliliğine işaret etmektedir (Arslan ve Kökocak, 2006, Aktaran, Alagöz vd., 2008: 80). Buna ilaveten Gerni vd., (2014), DYY'nin ekonomik ve siyasal liberalizasyona duyarlılığını ifade etmektedir. Buna göre, demokratikleşme ve hukukun üstünlügüne bağl1lı̆̆ın yabanc1 sermayeye güven veren temel unsur olduğu belirtilmektedir. Alagöz vd., (2008)'in çalışmalarında yer verilen literatürde, Carkovic ve Levine (2002), ülkelerin farklı seviyelerde olmaları durumunda DYY’lerin ekonomik büyüme üzerinde güçlü bir etkisinin olmayacağını ileri sürmektedir. Akinlo (2004), özel ve gecikmeli yabancı sermayenin ekonomik büyüme üzerinde istatistiksel olarak anlamlı bir etkisinin olmadığını belirtilmektedir. Buna karşılık ampirik çalışmaların çoğunda bazı şartlar altında DYY’lerin ülke ekonomileri üzerinde pozitif etkileri olduğu sonucu da paylaşılmaktadır. Borensztein vd., (1998) ile Xu (2000) ülkelerin eğitim düzeyinin yüksek olması durumunda DYY'lerin büyümeyi pozitif yönde 
etkilediğini vurgulamaktadır. Alfaro vd., (2004), Durham (2004) ve Hermes ve Lensink (2003), DYY’lerin büyüme üzerinde olumlu etkilerinin ancak ülkelerin gelişmiş finansal piyasalara sahip olmaları ile mümkün olacağını ileri sürdügünü belirtmektedir. Gruben ve Mclead (1998) ile Zhang (1999, 2001)'n ise DYY'lerin ekonomik büyümeyi teşvik ettiği sonuçlarını ortaya koymuşlardır.

Dereli (2018) tarafından derlenip rapor edilen ve farklı ülke örneklerinden oluşan çalışmaların genel sonuçları DYY'lerin büyümeye olan etkisini işaret etmektedir: Simionescu (2016), 28 AB ülkesinde 2008-2014 dönemi verileriyle DYY ile büyüme arasında karşılıklı ve pozitif bir ilişki tespit etmiştir. Batten ve Vo (2009), 1980-2003 döneminde 79 ülke örneğinde DYY'lerin ekonomik büyüme üzerinde güçlü bir pozitif etkisi olduğu sonucuna ulaşmışlardır. Hansen ve Rand (2006), 31 gelişmekte olan ülkeye yönelik olarak 1970-2000 dönemini kapsayan araştırmalarında panel eşbütünleşme ve Granger nedensellik testlerinden yararlanmışlar ve karşıllıklı nedensellik ilişkisinin yanı sıra, uzun dönemde yabancı sermaye yatırımlarının büyümeyi beslediği sonucuna ulaşmışlardır. Li ve Liu (2005), 1970-1999 dönemi için 84 ülkeyi dahil ettikleri panel veri analizinde DYY'nin ekonomik büyümeyi pozitif etkilediği sonucuna ulaşmışlardır. Chowdhury ve Mavrotas (2005) ise, Toda-Yamomato nedensellik testini kullanarak 1969-2000 döneminde Malezya, Şili ve Tayland'da ekonomik büyüme ile DYY ilişkisini Malzeya ve Tayland'da değişkenler arasında çift yönlü nedensellik ilişkisi vardır şeklinde rapor etmişlerdir. Choe (2003), 1971-1995 dönemi verileriyle ulaştığ 1 panel analizi ile 80 ülkede DYY ile büyüme arasındaki ilişkide, değişkenler arasında karşıllklı nedensellik ilişkisi olduğu sonucuna ulaşmıştır. Compos ve Kinoshita (2002), Orta ve Doğu Avrupa ile eski Sovyetler Birliği olmak üzere 25 ülke üzerine yaptıkları çalışmalarında DYY'lerin ekonomik büyümeyi olumlu etkilediğini tespit ettiklerini, çalışmalarının literatür kısmında rapor etmişlerdir.

Ağır ve Rutbil (2019), DYY ile ekonomik büyüme ilişkisini, sabit sermaye yatırımları kontrol değişkenini de kullanarak Türkiye ekonomisi örneğinde zaman serileri ekonometrisinin, etki- tepki, varyans ayrıştırması ve Granger nedensellik analizleri yardımıyla araştırmışlardır. Türkiye ekonomisi için, değişkenler arasında uzun dönemli bir ilişkinin olmadığ Johansen eşbütünleşme testi ile ortaya konulduktan sonra sonra, etki tepki varyans ayrıştırması ve Granger nedensellik tahminleri yaparak Türkiye ekonomisinde DYY'ler ile ekonomik büyüme arasında bir ilişkisinin olmadığını rapor etmişlerdir. $\mathrm{Bu}$ durumu da Türkiye'ye gelen DYY'lerin yetersizliğine vurgu yaparak açıklamışlardır.

Öncü ve Çelik (2018), DYY ile ekonomik büyüme arasındaki ilişkiyi BRICT ülkeleri için, iki değişkenle ve 1998-2016 dönemini için ele alarak tahmin etmiş, ekonomik büyümeden DYY'ye doğru tek yönlü nedensellik ilişkisi rapor 
edilmiştir. Boquiong ve Benjamin (2018), Meksika, Endonezya, Nijerya ve Türkiye için DYY ile ekonomik büyüme arasındaki ilişkiyi, 1990-2014 dönemi yıllık verileriyle ve enerji tüketimi, hisse senedi stoğu (capital stock) işgücü ve enflasyon değişkenlerini de kullanarak panel eşbütünleşme ve panel ECM analizleriyle tahmin etmiş, ülkelere özgü sonuçlar elde etmişlerdir. Kılıç ve Güllü (2018), sermaye değişkenini de ekleyerek Avusturalya, Rusya, Kanada, Şili, Çin, Endonezya, Japonya, Kore, Malezya, Meksika ve ABD ülkeleri olmak üzere 11 ekonomi için 1990-2016 dönemi verileriyle eşbütünleşme ve DYY'den ekonomik büyümeye doğru bir nedensellik ilişkisi tespit etmişlerdir.

Nur ve İlber (2017), 18 gelişmekte olan ülkeye ait DYY girişleri üzerinde etkili olduğu düşünülen 12 farklı değişkenle ve 1996-2014 döneminde, yolsuzluk kontrolü, dışa açıklık oranı, teknoloji, toplam işgücü ve hukukun üstünlüğü değişkenlerinin DYY girişlerini olumlu etkilediğini; borç stoku, gayri safi sabit sermaye ve altyapı değişkeninin ise DYY girişlerini olumsuz yönde etkilediği sonucuna ulaşmıştır. Alvarado, vd., (2017), çalışmalarında 19 Latin Amerika ülkesinde 1980-2014 dönemi verileriyle ve fiziksel sermaye ve işgücü değişkenleri ve sektörel göstergeler de eklenerek yapılan tahminde, DYY'nin ekonomik büyüme üzerinde açık bir şekilde etkisi rapor edilememiştir.

Bostan vd., (2016), çalışmalarında, Avrasya ülkelerindeki ekonomik büyüme süreci ile DYY'ler arasındaki nedensellik analizinde, ekonomik büyümeden DYY değişkenine doğru tek yönlü bir nedensellik iliş̧isi tespit etmişleridir. Abbes vd., (2015) gelişmekte olan 65 ülke için 1980-2010 dönemi y1llk verileriyle, DYY'den ekonomik büyümeye doğru tek yönlü nedensellik ilişkisi rapor etmişlerdir. Erol ve Çınar (2013), DYY'nin ekonomik büyüme ve gelir eşitsizliği üzerindeki etkisini, 17 gelişmekte olan ülke için (Arjantin, Brezilya, Şili, Kolombiya, Kosta Rica, Honduras, Meksika, Paraguay, Peru, Filipinler, Polonya, Romanya, Rusya, Tayland, Türkiye, Ukrayna, Uruguay) 1990-2011 döneminde kişi başına gelir, gini katsayısı, DYY oranı, ihracat oran1, ithalat oranı, brüt sabit sermaye yatırımları ve işgücüne katılım oranları değişkenlerini de kullanarak, DYY'nin kişi başına gelir üzerinde bir artışa yol açtı̆̆ bulgulanmıştır.

Erçakar ve Yılgör (2010) çalışmalarında, gelişmekte olan ülkeler arasından seçilmiş 19 ülke ve 1980-2005 döneminde incelemiş sonucunda ise azgelişmiş ülkelerde DYY ile gelir arasında uzun dönemli bir ilişki olduğu saptanmıştır. Okuyan ve Erbaykal (2007) DYY ile ekonomik büyüme arasındaki nedensellik ilişkisini, Brezilya, Singapur, Hindistan, Endonezya, Meksika, Malezya, Güney Kore, Tayland ve Türkiye ekonomilerinin verileriyle 1970-2006 dönemi için yıllık veri olarak incelenmişlerdir. Tahmin sonuçları; analize konu olan ülkelerden altı tanesinde ekonomik büyümeden DYY'lere doğru, bir tanesinde DYY'nin ekonomik büyümeye doğru ve iki tanesinde ise karşllıklı nedensellik 
ilişkisine rastlanıldığını rapor etmişlerdir. Yazarlar bu sonuçlardan hareketle gelişmekte olan ülkelerde doğrudan yabancı sermaye yatırımlarının ekonomik büyümenin bir sonucu olduğunu ileri sürmektedir.

Yukarıda sunulan literatür, gerek ülke örneklerinde gerekse ülke grupları ele alınarak incelenen çalışmalarda gelişmekte olan ülkelerde DYY ile ekonomik büyüme ilişkisi üzerine bir konsensüs oluşmadığını ortaya koymaktadır.

\section{EKONOMETRÍK ANALIZ}

Çalışmanın bu bölümünde Dünya Bankası sınıflandırmasında yer alan üst-orta gelir gurubu içerisindeki 20 ülke için panel ekonometrik tahminler yapılmaktadır. Örneklem olarak seçilen ülkeler, üst-orta gelir grubu içerisindeki, veri varlığı göz önünde bulundurularak belirlenmiş ve en fazla veriye sahip olan ülkelerden seçilmişlerdir. Öncelikle değişkenler tanıtılarak ekonometrik model oluşturulmaktadır. Sonra, Pesaran ve Yamagata (2008) tarafindan eğim katsayılarının homojen olup olmadığının test edilmesi amacıyla geliştirilen delta $(\Delta)$ testi aracılığıyla homojenlik testine yer verilmektedir. ${ }^{2}$ Değisşkenlerde kesitlerarası bağımlılı̆̆ test etmek için Breusch ve Pagan (1980) LM testi, Pesaran (2004) tarafindan geliştirilen CD ve CDLM testleri ile Pesaran vd. (2008) tarafından geliştirilen LMadj testi kullanılmaktadır. Panel birim kök testleri, Nazlıoğlu ve Karul (2017) tarafindan ileri sürülen, kademeli geçişe (ani olmayan kırılmalara) ve kesitlerareası bağımlılığa izin veren LM tipi Fourier panel birim kök testleri kullanılarak yapılmakta ve sonrasında ise Westerlund ve Edgerton (2008) yapısal kırılmaları dikkate alan panel eşbütünleşme testleri ve yatay kesit bağımlılığını dikkate alan Konya (2006) Nedensellik testleri kullanılarak analizler sonuçlandırılmaktadır.

\subsection{Değişkenlerin Açıklanması}

Ekonometrik tahminlerde kullanılacak olan gelir, doğrudan yabancı sermaye yatırımları ve sabit sermaye yatırımları değişkenleri için çeşitli açıklayıcı bilgiler Tablo 1'de açıklanmakta ve kurulan ekonometrik model ise Denklem 1'de sunulmaktadir.

Tablo 1. Değişkenlerin Açıklanması

\begin{tabular}{|c|c|c|c|}
\hline Simge & Açıklama & Dönem & Kaynak \\
\hline
\end{tabular}

\footnotetext{
${ }^{2} \mathrm{Bu}$ çalışmada kullanılan ekonometrik yöntemlerin metodolojik tartışmaları, sayfa sayısının arttırılmaması düşünülerek ihmal edilmiştir. Her bir testin metodolojik açıklamaları atıfta bulunulan orijinal makalelerde yer alırken, bu testlerin birlikte sunulduğu çalışmalar için de Bknz., Türkmen, 2019, Rutbil, 2019.
} 


\begin{tabular}{|c|c|c|c|}
\hline LGDP & $\begin{array}{l}\text { Logaritma } \\
\text { Kişi Başına GSYİH }\end{array}$ & $\begin{array}{l}\text { 1985-2017 } \\
\text { Y1ll1k }\end{array}$ & $\begin{array}{c}\text { Dünya } \\
\text { Bankas1 } \\
\text { WDI }\end{array}$ \\
\hline LFDI & $\begin{array}{l}\text { Logaritma } \\
\text { Doğrudan Yabancı Sermaye Girişi / } \\
\text { GSYİH }\end{array}$ & $\begin{array}{l}\text { 1985-2017 } \\
\text { Y1ll1k }\end{array}$ & $\begin{array}{l}\text { Dünya } \\
\text { Bankas1 } \\
\text { WDI }\end{array}$ \\
\hline LIN & $\begin{array}{l}\text { Logaritma } \\
\text { Sabit Sermaye Yatırımları / GSYİH }\end{array}$ & $\begin{array}{l}\text { 1985-2017 } \\
\text { Y1llik }\end{array}$ & $\begin{array}{c}\text { Dünya } \\
\text { Bankas1 } \\
\text { WDI }\end{array}$ \\
\hline
\end{tabular}

$$
\begin{aligned}
& L G D P_{i t}=\alpha_{i}+\beta_{1 i} L F D I_{i t}+\beta_{2 i} L I N_{i t}+\varepsilon_{i t} \\
& (i=1 \ldots, 20) \text { ve }(t=1985 \ldots, 2017)
\end{aligned}
$$

Ekonomik büyüme teorisi ve literatüründe ekonomik büyümeyi etkileyebilen değişkenler göz önüne alınarak, aynı zamanda bu çalışmanın literatür bölümünde tartışılan DYY ve ekonomik büyüme ilişkisine konu olan literatüründe ortaya konulan çalışmalardan yola çıkarak, DYY ve ekonomik büyümeyi temsil eden göstergelere ilaveten, kontrol değişkeni olarak her bir ülkenin sabit sermaye yatırımları (gross fixed capital formation) değişkeni de modele eklenmektedir.

\subsection{Homojenite Testi}

Ekonometrik analizlerde ilk olarak homojenlik testlerine yer verilmektedir. Pesaran ve Yamagata (2008) tarafindan önerilen Delta testi için hipotez şu şekilde oluşturulmaktadır:

$\mathrm{H}_{0}$ : Ĕgim Katsayıs1 Homojendir

$\mathrm{H}_{1}$ : Eğim katsayısı Homojen Değildir.

\begin{tabular}{|c|c|c|}
\hline & $\boldsymbol{\beta}_{1}$ & $\boldsymbol{\beta}_{2}$ \\
\hline Testler & $\begin{array}{l}\text { Test } \\
\text { İstatistiği }\end{array}$ & $\begin{array}{l}\text { Test } \\
\text { Istatistiği }\end{array}$ \\
\hline Delta Tilde & $\begin{array}{r}14.010 * * * \\
{[0.0000]}\end{array}$ & $\begin{array}{r}18.402 * * * \\
{[0.0000]}\end{array}$ \\
\hline $\begin{array}{l}\text { Delta } \\
\text { Tilde }_{\text {adj }}\end{array}$ & $\begin{array}{r}14.694 * * * \\
{[0.0000]}\end{array}$ & $\begin{array}{r}19.300 * * * \\
{[0.0000]}\end{array}$ \\
\hline
\end{tabular}

Tablo 2. Delta Testi Sonuçları

***\%1, seviyesinde anlamlılığ1, [] ise prob. değerini göstermektedir. 
Delta testlerinde sunulan istatistikler, boş hipotezi reddederek, hem $\boldsymbol{\beta}_{1}$ hem de $\boldsymbol{\beta}_{2}$ katsayılarının homojen olmadığını göstermektedir. Bu durum, seçilen ülke grubunda doğrudan yabancı yatırımlarda ve sabit sermaye yatırımlarında meydana gelen bir değişikliğin, ülkelerin ekonomik büyümeleri üzerinde farklı etkiler doğurduğunu ortaya koymaktadır. Dolayısıyla elde edilen bulgular, seçilen ülke grubunun heterojen bir yapıya sahip olduğunu göstermektedir.

\subsection{Yatay Kesit Bağımlılığı Testi}

Seriler arasında yatay kesit bağımlılı̆̆ın bulunması durumunda, bu durumun göz önünde bulundurulması elde edilen analiz sonuçlarını önemli ölçüde etkilemektedir (Breusch ve Pagan, 1980). Hipotez şu şekilde kurulmaktadır.

$\mathrm{H}_{0}$ : Yatay Kesit Bağımlılı̆̆ı Yoktur.

$\mathrm{H}_{1}$ : Yatay Kesit Bağımlılı̆̆ı Vardır.

Ampirik bulgulara göre sıfır hipotezinin $\left(\mathrm{H}_{0}\right.$ : “Kesitler arası bağımlılık yoktur") reddedilememesi, ülkeler arasında yatay kesit bağımlılığının olmadığını yani bir ülkede ortaya çıkan makroekonomik bir şokun diğer ülkeleri etkilemediğini göstermektedir. Bu durumda modele birinci nesil panel birim kök testleri uygulamak gerekmektedir. Ancak, sifir hipotezi reddedilir ve kesitler arası bağımlılığının olduğu tespit edilirse bu durumda da modele ikinci nesil panel birim kök testlerinin uygulanmas1 gerekmektedir (Baltagi, 2008: 284). Bu anlamda, yatay kesit bağımlılığı testleri, serilerin birim kök içerip içermediğini, birinci nesil mi yoksa ikinci nesil testlerle mi sınamanın doğru olacağına karar vermeye olanak sağlamaktadır.

Değişkenlerde kesitlerarası bağımlılığı test etmek için Breusch ve Pagan (1980) LM testi, Pesaran (2004) tarafından geliştirilen CD ve CDLM testleri ile Pesaran vd. (2008) tarafından geliştirilen LMadj testi kullanılmıştır.

Tablo 3. Yatay Kesit Bağımlılı̆̆ Testi

\begin{tabular}{|c|c|c|}
\hline Testler & $\begin{array}{l}\text { İstistik } \\
\text { Değeri }\end{array}$ & $\begin{array}{l}\text { Olasılık } \\
\text { Değgeri }\end{array}$ \\
\hline $\mathrm{CD}_{\operatorname{lm}}(\mathrm{BP}, 1980)$ & $1330.346^{* * *}$ & 0.000 \\
\hline $\mathrm{CD}_{\operatorname{lm}}$ (Pesaran, 2004) & $58.499^{* * *}$ & 0.000 \\
\hline $\mathrm{CD}_{\operatorname{lm}}$ (Pesaran, 2004) & $32.345^{* * *}$ & 0.000 \\
\hline $\mathrm{LM}_{\text {adj }}$ (PUY, 2008) & $57.458^{* * *}$ & 0.000 \\
\hline
\end{tabular}

Tablo 3'te yer alan yatay kesit bağımlılığ düzeyinde kesitler arası bağımlılık olduğu sonucuna ulaşılmıştır. Elde edilen 
sonuca göre, bir ülkede ortaya çıkan bir değişiklik (şok) diğer ülkeleri de etkileyebilmektedir.

Kesitler arası bağımlılı̆̆ dikkate almamak, makro ekonomik şokların paneli oluşturan tüm ülkeleri etkilemediğini varsaymaktır. Ancak bu karşılaşılan bir durum değildir. $\mathrm{Bu}$ sebeple, bulguların etkinliği için kesitler arası bağımlılığı dikkate alan ikinci nesil panel birim kök testlerinin uygulanması gerekmektedir (Nazlıŏlu, 2010: 142).

\subsection{Panel Birim Kök Testleri}

Geleneksel birim kök testlerinin halen kullanılıyor olmasıly birlikte son yıllarda, özellikle yatay kesit bağımlılı̆̆ analizleri ile birlikte yeni nesil (ikinci nesil) birim kök testlerinin kullanılması zorunlu hale gelmektedir. Bu çalışmada yapısal kırılmaları da dikkate alan panel birim kök testlerinden yararlanılmaktadır. Yapısal kırılmalı birim kök testlerinin güvenilirliği için en önemli husus kırılma tarihlerinin, sayılarının ve formlarının isabetli bir şekilde önceden tespit edilebilmiş olmasıdır. Burada meydana gelebilecek güçlükler Fourier birim kök testleri ile aşılmaya çalışılmaktadır. Zira bu tip testler sadece sert kırılmalara değil kademeli (gradual) kırılmalara (yumuşak geçişlere) da izin vermektedir ve testin modellenmesi aşamasında kırılma formunun ve tarihlerinin önceden biliniyor olmasına gerek duymamaktadır.

$\mathrm{Bu}$ çalışmanın analiz sonuçları, ikinci nesil panel birim kök testlerini uygulamaya olanak sağlamaktadır. Bu çalışmada uygulanan nihai test yöntemi ise Nazlıoğlu ve Karul (2017) kademeli geçişe ve kesitler arası bağımlılığa izin veren ikinci nesil Fourier LM tipi panel birim kök testidir (Fourier Panel LM). Söz konusu testin boş hipotezi "birim kök vardır" varsayımı üzerine kuruludur. Tablo 4-6.'da ampirik analizde kullanılan değişkenler için uygulanan birim kök testleri tahminleri yer almaktadır:

Tablo 4. LGDP Değişkeni Fourier LM Birim Kök Testi Sonuçları

\begin{tabular}{lrrr}
\hline Ülkeler & $\boldsymbol{k}=\mathbf{1}$ & $\boldsymbol{k}=\mathbf{2}$ & $\boldsymbol{k}=\mathbf{3}$ \\
\hline Cezayir & -0.492 & 0.001 & 1.625 \\
Belize & -1.074 & -2.917 & -1.828 \\
Botsvana & -1.061 & -2.489 & -2.962 \\
Brezilya & -0.960 & -1.360 & -0.637 \\
Cin & 0.883 & 1.584 & 0.588 \\
Kolombiya & -0.073 & 0.042 & -0.727 \\
Kosta Rika & -0.859 & -0.158 & -1.182 \\
Dominik & -0.773 & -1.541 & -1.746 \\
Cumhuriyeti & & & \\
Ekvador & -0.044 & 0.685 & 0.057 \\
\hline
\end{tabular}




\begin{tabular}{lrrr}
\hline Guyana & -0.314 & 0.050 & -0.221 \\
Jamaika & -1.951 & -3.191 & -2.553 \\
Ürdün & -1.882 & -0.739 & -0.546 \\
Malezya & 0.487 & 0.402 & -0.252 \\
Mauritius & -2.741 & -3.178 & -2.379 \\
Meksika & -0.569 & -1.128 & -1.013 \\
Paraguay & -1.043 & -0.934 & -0.021 \\
Peru & -0.387 & -0.385 & -0.736 \\
Güney Afrika & -1.314 & -0.343 & -1.366 \\
Tayland & -0.807 & -0.196 & -1.490 \\
Türkiye & -1.265 & -1.175 & -0.641 \\
Panel Sonuçları & & & \\
ZLMIStatistiğ $i_{\text {Olasllik Değeri }}$ & 15.564 & 8.430 & 7.980 \\
\hline
\end{tabular}

Tablo 4'te sunulan Fourier LM testi istatistikleri, $H_{0}$ boş hipotezinin kabul edileceğini ve dolayısıyla LGDP değişkeninin seviyede birim kök içerdiğini göstermektedir.

Tablo 5. LFDI Değişkeni Fourier LM Birim Kök Testi

\begin{tabular}{lrrr}
\hline Ülkeler & $\boldsymbol{k}=\mathbf{1}$ & $\boldsymbol{k}=\mathbf{2}$ & $\boldsymbol{k}=\mathbf{3}$ \\
\hline Cezayir & -1.731 & -0.438 & -0.276 \\
Belize & -3.621 & -0.772 & -0.886 \\
Botsvana & -1.315 & -0.259 & 0.011 \\
Brezilya & 0.373 & -0.135 & 0.440 \\
Çin & 0.319 & 1.132 & 1.704 \\
Kolombiya & -3.169 & -0.924 & -0.732 \\
Kosta Rika & -4.377 & -1.230 & -1.414 \\
Dominik & -1.822 & -2.001 & -3.126 \\
Cumhuriyeti & & & \\
Ekvador & -2.255 & -3.654 & -4.579 \\
Guyana & -1.394 & -2.062 & -2.188 \\
Jamaika & -0.871 & -2.251 & -2.213 \\
Urrdün & -4.796 & -1.581 & -1.431 \\
Malezya & -4.480 & -3.199 & -3.381 \\
Mauritius & -3.464 & -1.185 & -1.567 \\
Meksika & -1.876 & -4.101 & -2.329 \\
Paraguay & -1.876 & -1.422 & -1.308 \\
Peru & -0.047 & 0.476 & 0.951 \\
Güney Afrika & -0.940 & -0.454 & -0.233 \\
Tayland & -3.752 & -4.398 & -2.211 \\
\hline
\end{tabular}




\begin{tabular}{lccc}
\hline Türkiye & -3.458 & -0.957 & -1.437 \\
Panel Sonuçları & & & \\
$Z_{\text {LMIStatistiğ } i}$ & 5.266 & 4.594 & 5.193 \\
Olasılık Değeri & 1.000 & 1.000 & 1.000 \\
\hline
\end{tabular}

Tablo 5'te sunulan Fourier LM istatistikleri, $H_{0}$ boş hipotezinin reddedilemez olduğunu dolayısıyla LFDI değişkenin de LGDP değişkeninde olduğu gibi, seviyede birim kök içerdiğini göstermektedir.

Tablo 6. LIN Değişkeni Fourier LM Birim Kök Testi

\begin{tabular}{lrrr}
\hline Ülkeler & $\mathbf{k}=\mathbf{1}$ & $\boldsymbol{k}=\mathbf{2}$ & $\mathbf{k = 3}$ \\
\hline Cezayir & -1.763 & -1.393 & -0.976 \\
Belize & -2.191 & -1.694 & -2.084 \\
Botsvana & -3.282 & -2.744 & -4.523 \\
Brezilya & -3.127 & -3.260 & -3.993 \\
Çin & -2.316 & -2.612 & -2.186 \\
Kolombiya & -3.241 & -2.779 & -3.502 \\
Kosta Rika & -1.078 & -2.145 & -1.261 \\
Dominik & -2.327 & -1.575 & -3.541 \\
Cumhuriyeti & & & \\
Ekvador & -1.424 & -1.873 & -1.697 \\
Guyana & -3.158 & -2.968 & -3.398 \\
Jamaika & -3.876 & -1.632 & -2.135 \\
Ürdün & -2.967 & -2.471 & -2.126 \\
Malezya & -0.673 & -2.338 & -0.431 \\
Mauritius & -1.284 & -1.683 & -2.505 \\
Meksika & -3.369 & -4.316 & -3.422 \\
Paraguay & -2.766 & -1.615 & -1.938 \\
Peru & -1.321 & -2.175 & -0.121 \\
Güney Afrika & -0.729 & -1.091 & -1.854 \\
Tayland & -1.703 & -1.972 & -2.546 \\
Türkiye & -1.217 & -2.288 & -0.462 \\
Panel Sonuçları & & & \\
ZLM Istatistiği & & -0.096 & -1.113 \\
Olasıllk Değeri & 5.536 & 0.462 & 0.133 \\
\hline
\end{tabular}

Tablo 6'da sunulan Fourier LM testi sonuçları da ekonometrik araştırma kullanılan diğer değişkenler gibi boş hipotezi kabul ederek LIN değişkeninin de seviyede birim kök içerdiğini göstermektedir. LGDP, LFDI ve LIN değişkenlerinin üçü de seviyede birim kök içeren değişkenlerdir. 


\subsection{Panel Eş Bütünleşme Testleri}

Analizde, paneldeki serilerin seviyede (düzeyde) birim kök içerdiği göz önüne alınarak, Westerlund ve Edgerton (2008)'un yapısal kırılmalı eşbütünleşme testi uygulanmaktadır. $\mathrm{Bu}$ test, Lagrange Multiplier (LM) temelli, (Schmidt ve Phillips (1992), Ahn (1993) ve Amsler ve Lee (1995)) birim kök testlerinden geliştirilmiş ve değişen varyans (heteroscedastisity) ve otokorelasyona (serial correlation) da izin vermektedir. Öte yandan Westerlund ve Edgerton (2008) tarafından geliştirilen bu test sabit terimde ve eğimde (trend) her bir ülke için farklı tarihlerdeki kırılmalara da olanak sağlamaktadır. Tablo 7'de seçilmiş ülkeler üzerine uygulanan yatay kesit bağımlılığını ve yapısal kırılmaları göz önünde bulunduran yapısal kırılmalı eş bütünleşme test sonuçlarına yer verilmektedir, kırılma tarihleri ayrıca rapor edilmemektedir.

Tablo 7. Yapısal Kırılmalı Eşbütünleşme Testi (Westerlund \& Edgerton, 2008)

\begin{tabular}{|l|r|r|}
\hline \multicolumn{1}{|c|}{ Model } & $\boldsymbol{Z}_{\tau}(\mathbf{N})$ İstatistiği\& Prob. & $\boldsymbol{Z}_{\varphi}($ N) İstatistiği \& Prob. \\
\hline Kırılmasız & $-0.113[0.454]$ & $0.207[0.582]$ \\
\hline Sabitte Kır1ma & $0.225[0.589]$ & $1.220[0.888]$ \\
\hline Rejim Kırılmas1 & $0.280[0.610]$ & $1.521[0.936]$ \\
\hline
\end{tabular}

Elde edilen $\mathrm{Z}_{\tau}(\mathrm{N})$ ile $\mathrm{Z}_{\varphi}(\mathrm{N})$ istatistikleri, $\mathrm{H}_{0}$ : Eşbütünleşme yoktur, şeklinde kurulan boş hipotezi kabul etmektedir. Dolayısıyla her iki istatistik değerine göre değişkenler arasında uzun dönemli bir ilişki olmadığı bulgusu elde edilmektedir. Seriler eşbütünleşik değildirler.

\subsection{Panel Nedensellik Testleri}

Panel nedensellik testleri olarak Konya (2006) tarafindan geliştirilen nedensellik testlerinden yararlanılmaktadır. Elde edilen istatistikler Tablo 8.'de sunulmaktadır. Tablo 8.'de her bir ülkeyi göstermesi açısından hesaplanan Wald istatistiği ve olasık değerlerinin yanı sıra, tüm panelin göstergesi olarak hesaplanan Panel Fisher istatistiği yer almaktadır. Boş hipotezin LFDI $\rightarrow$ LGDP (LGDP LFDI'ın Granger nedeni değildir) ve LGDP $\rightarrow$ LFDI (LFDI LGDP'nin Granger nedeni değildir) şeklinde kurulduğu test sonuçları, her iki değişkenin de karşılıklı olarak birbirlerinin nedeni olmadıklarını Panel Fisher istatistikleriyle ortaya koymaktadır. Başka bir ifadeyle panelin tamamı için Panel Fisher istatistiğinin sonucu boş hipotezin kabul edildiğini ortaya koymaktadır. Hek DYY ekonomik büyümenin nedeni değilken, hem de ekonomik büyüme DYY'nin nedeni değildir. Buna ilaveten sonuçlar ülke bazında incelendiğinde de Cezayir, Çin, Kosta Rika, Guyana, Peru ve Türkiye'de DYY'den ekonomik 
büyümeye doğru nedensellik ilişkisinin varlığı Tablo 8'de sunulan istatistikler aracılığıla ortaya konulmaktadır.

Tablo 8. Panel Granger Nedensellik Test Sonuçları - Konya (2006)

\begin{tabular}{|l|c|c|c|c|}
\hline \multirow{2}{*}{ Ülke Sonuçlart } & \multicolumn{2}{|c|}{ LFDI $\rightarrow$ LGDP } & \multicolumn{2}{c|}{ LGDP $\rightarrow$ LFDI } \\
\cline { 2 - 5 } & $\begin{array}{c}\text { Wald } \\
\text { Istatistiği }\end{array}$ & $\begin{array}{c}\text { Olasıllk } \\
\text { Değeri }\end{array}$ & $\begin{array}{c}\text { Wald } \\
\text { Istatistiği }\end{array}$ & $\begin{array}{c}\text { Olasılık } \\
\text { Değeri }\end{array}$ \\
\hline Cezayir & $6.840^{* *}$ & 0.010 & 0.140 & 0.570 \\
\hline Belize & 11.487 & 0.240 & 0.086 & 0.920 \\
\hline Botsvana & 3.248 & 0.730 & 0.029 & 0.900 \\
\hline Brezilya & 0.709 & 0.620 & 10.144 & 0.130 \\
\hline Çin & $90.460^{* * *}$ & 0.000 & $3.953^{* *}$ & 0.020 \\
\hline Kolombiya & 0.618 & 0.770 & 20.268 & 0.150 \\
\hline Kosta Rika & $8.797^{*}$ & 0.070 & 0.193 & 1.000 \\
\hline $\begin{array}{l}\text { Dominik } \\
\text { Cumhuriyeti }\end{array}$ & 1.659 & 0.450 & 9.738 & 0.310 \\
\hline Ekvador & 3.805 & 0.390 & 2.284 & 0.410 \\
\hline Guyana & $29.366^{* * *}$ & 0.000 & 0.001 & 0.960 \\
\hline Jamaika & 2.165 & 0.280 & 5.204 & 0.750 \\
\hline Ürdün & 34.024 & 0.360 & 0.675 & 1.000 \\
\hline Malezya & 5.335 & 0.730 & 0.278 & 0.700 \\
\hline Mauritius & 10.250 & 0.580 & 8.956 & 0.450 \\
\hline Meksika & 0.311 & 0.760 & $30.159 *$ & 0.080 \\
\hline Paraguay & 4.562 & 0.220 & 1.306 & 0.550 \\
\hline Peru & $16.814^{*}$ & 0.060 & 2.785 & 0.650 \\
\hline Güney Afrika & 0.236 & 0.680 & 9.112 & 0.120 \\
\hline Tayland & 0.009 & 0.970 & 0.145 & 0.800 \\
\hline Türkiye & $50.217^{* * *}$ & 0.000 & 10.599 & 0.740 \\
\hline Panel Fisher & $\mathbf{3 9 . 3 1 6}$ & $\mathbf{0 . 5 0 1}$ & $\mathbf{3 6 . 6 9 1}$ & $\mathbf{0 . 6 2 0}$ \\
\hline
\end{tabular}

\section{SONUÇ}

Teorik olarak doğrudan yabancı sermaye yatırımlarının gittiği ülkelerde ekonomik büyümeye olumlu katkı sağlaması beklenmekle birlikte, literatürden elde edilen sonuçlarda bir bütünlük bulunmamaktadır.

$\mathrm{Bu}$ çalışmada yeni nesil panel ekonometrik analizlerden yararlanılarak seçilmiş gelişmekte olan ülkelerde doğrudan yabancı sermaye yatırımları ile ekonomik büyüme arasındaki ilişki yeni nesil panel analiz yöntemleriyle ve panel 
eşbütünleşme ve panel nedensellik analizleri yardımıyla ortaya konulmuştur. Elde edilen sonuçlar söz konusu ülkelerde doğrudan yabancı sermaye yatırımlarının ekonomik büyümeye katkı sağlamadığı şeklindedir. Bu durum, veri ülkelerin birbirinden farklı makroekonomik özelliklere sahip olmalarından, söz konusu ülkelere doğru gelen doğrudan yabancı sermaye yatırımlarının, iyi bir şekilde planlanamamasından, etkin bir şekilde yönlendirilememesinden ve dahası doğrudan yabancı sermaye yatırımlarının yetersizliğinden de kaynaklanıyor olabilir.

Gelişmekte olan ülkeler daha fazla doğrudan yabancı sermaye yatırımlarını alabilmeleri için, makroekonomik performanslarını iyileştirmeli, demokratikleşme süreçlerine önem göstererek hukukun üstünlüğünü sağlamaları gerekmektedir. Finansal piyasalarının gelişimini desteklemeli ve dünyaya entegre etmeli ve olmalı ve eğitim düzeyini de arttırmalıdırlar. Başka bir ifadeyle ülkeye gelen DYY'lerin ekonomik büyümeye olumlu katkı sağlayabilmeleri için gelişmekte olan ülkelerin planl1-uygun-destekleyici programlar eşliğinde yatırım ortamını iyileştirmeli, ve minimum bir ekonomik gelişme \& kalkınma düzeyine erişmiş olmaları gerekmektedir.

\section{KAYNAKÇA}

Abbes, Sahraoui Mohammed, Mostéfa, Belmokaddem, Seghir, Guelli Mohammed and Zakarya, Ghouali Yassine (2015), “Causal Interactions between FDI and Economic Growth: Evidence From Dynamic Panel Co- Integration, Procedia Economics and Finance”, 23, pp. 276-290, https://www.sciencedirect.com/science/article/pii/S2212567115005419, 12.04.2019.

Ağır, Hüseyin ve Rutbil, Merve (2019), “Türkiye'de Doğrudan Yabancı Yatırımlar ve Ekonomik Büyüme İliş̧isi” II. KAYES, 11-12 Nisan, Kahramanmaraş

Akyol, Derya (2013), "Doğrudan Yabancı Yatırımların Makroekonomik Etkileri; Türkiye Ve Brezilya Karşılaştırması”, Sosyal Bilimler Enstitüsü, İşletme Yönetimi Anabilim Dalı, Yüksek Lisans Tezi, Ankara.

Alagöz, Mehmet, Erdoğan, Savaş. ve Topall1, Nurgün (2008), "Doğrudan Yabancı Sermaye Yatırımları ve Ekonomik Büyüme: Türkiye Deneyimi 1992-2007”, Gaziantep Üniversitesi Sosyal Bilimler Dergisi 7 (1), ss. 79-89.

Alvarado Rafael, Iniquez Maria and Ponce, Pablo, (2017), "Foreign Direct Investment and Economic Growth in Latin America", Economic Analysis and Policy 56, pp. 176-187. 
Aydın, Rahman (2015), "Doğrudan Yabancı Yatırımlar ile Ekonomik Büyüme Arasındaki İlişki: Türkiye Örneği”, Karadeniz Teknik Üniversitesi, Sosyal Bilimler Enstitüsü, Ekonometri Anabilim Dalı, Yüksek Lisans Tezi, Trabzon.

Bal, Harun ve Göz, Devlet (2010), “Doğrudan Yabancı Sermaye Yatırımları ve Türkiye’', Çukurova Üniversitesi, Sosyal Bilimler Enstitüsü Dergisi, 19 (2), ss. 450-467.

Baltagi, Badi Hani (2008), Econometric Analysis of Panel Data (4. Bask1), Great Britain: John Wiley Publication.

Bayraktar, Fulya (2003), "Dünyada ve Türkiye'de Doğrudan Yabancı Sermaye Yatırımları", Türkiye Kalkınma Bankası A.S. Genel Araştırmalar, ss. 1-82.

Bostan, Aziz, Ürüt Kelleci, Serap ve Yılmaz, Alper (2016), “Doğrudan Yabancı Sermaye Yatırımları ve Ekonomik Büyüme Arasındaki İlişki: Avrasya Ekonomileri Örneği”, MANAS Sosyal Araştırmalar Dergisi, 5 (5), ss. 23-36.

Breusch, Trevor Stanley and Pagan, Adrian Rodney (1980), The Lagrange Multiplier Test and its Applications to Model Specification in Econometrics. The Review of Economic Studies, 47 (1), 239-253.

Dereli, Deniz Dilara (2018), “Doğrudan Yabancı Sermaye Yatırımları İle Ekonomik Büyüme İlişkisi Üzerine Bir Değerlendirme: Türkiye (1995-2017)", C.Ü. İktisadi ve İdari Bilimler Dergisi, 19 (2), ss. 145-156.

Erçakar, Mehmet Emin ve Yılgör, Metehan (2010), “Gelişmekte Olan Ülkelerde DYY GSYİH İlişkisi: Panel Birim Kök ve Eş Bütünleşme Sınamaları" Finans Politik \& Ekonomik Yorumlar, 47 (549), ss. 31

Erol, Ece ve Çınar, Serkan (2013), "Doğrudan Yabancı Yatırımların Analizi ve Gelir İlişkisi: Gelişmekte Olan Ülkeler Örneği”, AİBÜ Sosyal Bilimler Enstitüsü Dergisi, 13 (1), ss. 17-36.

Gerni, Cevat, Sarı, Selahattin, Emsen, Ömer Selçuk, ve Kabadayı, Burhan (2014), "Geçiş Ekonomilerine Yönelik Doğrudan Yabancı Sermaye Yatırımları: İhracata Yönelik mi Yoksa İthalata Yönelik mi?”, International Conference on Eurasian Economies, ss. 1-10, https://www.avekon.org/papers/968.pdf, 10.04.2019

Kılıç, Nazife Özge and Güllü, İlhan (2018), "Relation of Foreign Direct Investment and Economic Growth-Panel Data Analysis on APEC 
Countries", Press Academia 5 (3), pp. 261-267. http://dergipark.gov.tr/download/article-file/544628, 14.04.2019.

Kónya, Laszlo (2006), "Exports and growth: Granger causality analysis on OECD countries with a panel data approach", Econonomic Modelling, 23 (6), pp. 978-992.

Lin, Boquiong and Benjamin, I. Nelson (2018), “Causal Relationship Between Energy Consumption Foreign Direct Investment and Economic Growth for MINT Evidence From Panel Dynmic Ordinary Least Square Models”, Journal of Cleaner Production, 197 (1), pp. 708-720. https://www.sciencedirect.com/science/article/pii/S095965261831802X, 14.04.2019.

Mucuk, Mehmet ve Demirsel, Mustafa, Tahir, (2009), “Türkiye'de Doğrudan Yabancı Yatırımlar ve Ekonomik Performans”, Selçuk Üniversitesi, Sosyal Bilimler Enstitüsü Dergisi, 21, ss. 365-373.

Nazlıoğlu, Şaban and Karul, Çağın (2017), "Panel LM Unit Root Test with Gradual Structural Shifts”, International Panel Data Conference, (IPDC2017), July 7-8, Thessaloniki-Grece.

Nazlığlu, Şaban (2010), Makro İktisat Politikalarının Tarım Sektörü Üzerindeki Etkileri: Gelişmiş Ve Gelişmekte Olan Ülkeler İçin Bir Karşılaştırma, Yayınlanmamış Doktora Tezi, T.C. Erciyes Üniversitesi Sosyal Bilimler Enstitüsü, Kayseri.

Nur, Hayriye Baş̧̧ ve Dilber, İlkay (2017), “Gelişmekte Olan Ülkelerde Doğrudan Yabancı Yatırımları Belirleyen Temel Unsurlar” Dokuz Eylül Üniversitesi İktisadi ve İdari Bilimler Fakültesi Dergisi 32 (2), ss. 15-45

Okuyan, Hamdi Aydın ve Erbaykal, Erman (2007), “Gelişmekte Olan Ülkelerde Doğrudan Yabancı Yatırımlar ve Ekonomik Büyüme İlişsisi”, Ekonomik Yaklaşım, 19 (67), ss. 47-58

Öncü, Erdem ve Çelik, Şaban (2018), “Doğrudan Yabancı Yatırım ve Ekonomik Büyüme İlişkisi: BRICT Ülkeleri Panel Nedensellik Analizi”, UiIIID-IJEAS, 2018 (17. UİK Özel Sayısı):403-414 ISSN 13079832, http://dergipark.gov.tr/download/article-file/506558, ss. 403-414.

Özdemir, Burak (2011), “Türkiye'de Faaliyet Gösteren Doğu Kökenli Yabancı Firmalar Üzerine Bir Araştırma", Balıkesir Üniversitesi, 
Sosyal Bilimler Enstitüsü, İşletme Anabilim Dalı, Yüksek Lisans Tezi, Balikesir.

Özkan, Bülent (2005), "Doğrudan Yabancı Sermaye Yatırımlarını Belirleyen Faktörler: İşletme ve İşveren Profili Açısından Gaziantep İli Örneği”, Dumlupınar Üniversitesi, Sosyal Bilimler Enstitüsü İktisat Anabilim Dalı, Doktora Tezi, Kütahya.

Pesaran, Mohammad Hashem, (2004), General Diagnostic Tests for Cross Section Dependence in Panels. (No. 1240), Institute for the Study of Labor (IZA).

Pesaran, Mohammad Hashem and Yamagata, Takashi (2008), “Testing Slope Homogeneity in Large Panels”, Journal of Econometrics, 142(1), pp. 5093.

Pesaran, Mohammad Hashem, Ullah, Aman and Yamagata, Takashi. (2008), “A Bias-adjusted LM Test of Error Cross-section Independence", Econometrics Journal. 11, ss.105- 127.

Rutbil, Merve (2019), "Gelişmekte Olan Ülkelerde Doğrudan Yabancı Sermaye Yatırımları ile Ekonomik Büyüme İlişkisinin Analizi”, Kahramanmaraş Sütçü İmam Üniversitesi Sosyal Bilimler Enstitüsü, Yüksek Lisans Tezi, Kahramanmaraş.

Sabır, Hasan (2001), "Doğrudan Yabancı Sermaye Yatırımlarını Geliştirmekte olan Ülkelere Yönlendirici Politikalar”, Hazine Müsteşarlığı Dergisi, 26, ss. 20- 28.

Seyidoğlu, Halil (2017), Uluslararası İktisat Teori Politika ve Uygulama, Güzel Can Yayınları, İstanbul.

Taban, Sami (2014), İktisadi Büyüme, Kavram ve Modeller, Üçüncü Basım, Nobel Yayınevi, Ankara.

Tandırcıoğlu, Haluk ve Özen, Ahmet (2003), "Geçiş Ekonomilerinde Doğrudan Yabancı Sermaye Yatırımları”, Dokuz Eylül Üniversitesi, Sosyal Bilimler Enstitüsü Dergisi, 5 (4), ss. 105-129.

Türkmen, Sena (2019), “Enerjide Çevresel Sürdürülebilirlik: Yükselen ve Gelişmiş Ekonomiler Karşılaştırması” Kahramanmaraş Sütçü İmam Üniversitesi Sosyal Bilimler Enstitüsü, Doktora Tezi, Kahramanmaraş. 
Westerlund, Joakim and Edgerton, David L., (2008), A simple test for cointegration in dependent panels with structural breaks. Oxford Bulletin of Economics and Statistics 70(5), pp. 665- 704.

Yılmaz, Mustafa (2008), "Gelişmekte Olan Ülkelerde Doğrudan Yabancı Yatırımlar-Ekonomik Büyüme İlişkisi: Panel Veri Analizi” T.C. Dokuz Eylül Üniversitesi Sosyal Bilimler Enstitüsü İktisat Anabilim dalı yayımlanmamış Yüksek Lisans Tezi. 